\title{
Penurunan Stres Ibu Pada Saat Masa Pandemi Covid 19 Di Posyandu Kunir V Wirobrajan Melalui Terapi Relaksasi Hipnosis 5 Jari dan Musik (Hypnofivesic) \\ Rizqi Wahyu Hidayati ${ }^{1}$, Novita Nirmalasari ${ }^{2}$, Latifah Susilowati ${ }^{3}$ \\ ${ }^{1,2,3}$ Keperawatan (S1), Fakultas Kesehatan, Universitas Jenderal Achmad Yani, Yogyakarta, Indonesia
}

e-mail: ${ }^{1}$ rizqiwahyu2989@gmail.com, ${ }^{2}$ novitanirmalasari@gmail.com, ${ }^{3}$ latsa7ers@yahoo.com

\begin{abstract}
ABSTRAK Stres di masa pandemi merupakan ketakutan dan kecemasan tentang kesehatan diri maupun kesehatan orang lain yang disayangi. Seseorang yang mengalami stress akan timbul gejala seperti perubahan pola tidur, pola makan, dan kesulitan konsentrasi. Faktor penyebab stres pada ibu antara lain adanya double burden yang terdiri pengasuhan anak, ibu rumah tangga, dan ibu bekerja. Sehingga manajemen stres dibutuhkan untuk mengurangi stres tersebut. Manajemen yang digunakan yaitu hypnosis lima jari dan terapi musik. Sehingga, pengabdian ini bertujuan untuk menurunkan level stres ibu selama masa pandemi. Pengabdian ini menggunakan metode pengajaran langsung dengan dibantu video terapi pada ibu. Sebelum dan sesudah kegiatan nilai stres ibu diukur menggunakan Perceived Stress Scale (PSS). Rata-rata itu mengalami stres sedang baik sebelum dan sesudah terapi. Selain itu, nilai $p$ value juga menunjukkan $0,802(p>0,05)$. Hal ini berarti bahwa terapi relaksasi yang dilakukan tidak memberikan penurunan secara bermakna. Maka, perlu dilakukan kegiatan tindak lanjut untuk mengatasi masalah tersebut.
\end{abstract}

\section{KATA KUNCI: Stres; Ibu; Covid-19; Hipnosis 5 Jari; Terapi Musik}

ABSTRACT Stress during a pandemic was fearful and anxiety about own health and the loved ones. A person who experiences stress, they had experience symptoms such as sleep disturbance, dietary disorder, and difficulty concentrating. Factors that caused stress to mothers include the double burden of childcare, housewives, and working from home. Stress management was needed to reduce stress. The relaxation managements were hypnosis and music therapy. Thus, this service aimed to reduce the stress level of mothers during the pandemic. It used direct teaching methods which assisted by therapeutic videos for mothers. Before and after this activity, the mothers' stress level measured using the Perceived Stress Scale (PSS). The result, they experienced moderate stress both before and after therapy. Besides that, the $p$ value also shows 0, 802 ( $p>0.05$ ). This means that the relaxation therapy carried out does not provide a significant reduction. So, it is necessary to carry out follow-up activities to overcome the problem.

\section{KEYWORDS: Stress; Mothers; Covid-19; Hypnosis; Music Therapy}

\section{Pendahuluan}

Stres di masa pandemi merupakan ketakutan dan kecemasan tentang kesehatan diri maupun kesehatan orang lain yang disayangi. Seseorang yang mengalami stress akan timbul gejala seperti perubahan pola tidur, pola makan, dan kesulitan konsentrasi. Stres pandemi juga dapat diperparah pada orang dengan penyakit komorbit dan penggunaan obat-obatan.[1] Hal ini memiliki dampak antara lain 
seseorang mengalami isolasi diri, kesepian, hingga depresi. Salah satu penyebabnya yaitu adanya pengaruh social distancing yang diterapkan selama pandemi tersebut. Stres yang dialami ibu diperbesar dengan adanya pembatasan gerak anak. Padahal, secara sosial, pergaulan untuk anak dibutuhkan dalam proses tumbuh kembangnya secara sosial. Beberapa hal yang dapat berdampak yaitu kesehatan, kesejahteraan, perkembangan, dan masa depan anak.[2]

Selain itu, stressor ibu juga diperparah dengan adanya proses pengasuhan anak selama pandemi Covid-19. Hal ini dijelaskan oleh Kurniati (2020) bahwa ibu memiliki peran menjaga dan memastikan anak untuk menerapkan hidup bersih dan sehat, mendampingi anak dalam mengerjakan tugas sekolah, melakukan kegiatan bersama selama di rumah, menciptakan lingkungan yang nyaman untuk anak, menjalin komunikasi yang intens dengan anak, bermain bersama anak, menjadi role model bagi anak, memberikan pengawasan pada anggota keluarga, menafkahi dan memenuhi kebutuhan keluarga, dan membimbing dan memotivasi anak, memberikan edukasi, memelihara nilai keagamaan, melakukan variasi dan inovasi kegiatan di rumah. Diperlukan panduan bagi orang tua dalam membantu mendampingi kegiatan anak yang berbasis pada kebutuhan anak selama pandemi dan bekerja dari rumah (BDR).

Fenomena stress ibu dengan balita banyak dirasakan. Hal ini terbukti dari beberapa ibu di Posyandu Kunir V yang mengatakan bahwa saat pandemi ini mereka memiliki peran yang lebih banyak. Peran tersebut yaitu sebagai ibu rumah tangga, ibu bekerja, dan guru. Hal ini dikarenakan TK dan PAUD dilakukan secara daring. Hal ini menambah beban bagi mereka. Sehingga, beberapa ibu yang memiliki 2 balita misalnya, mereka mengaku bahwa sering kurang konsentrasi, kelelahan, ketidakstabilan emosi, dan kurang istirahat.

Oleh karena itu manajemen stress perlu dilakukan pada ibu untuk mengurangi stress yang dialami. Salah satu yang dapat dilakukan yaitu dengan melakukan latihan relaksasi, salah satunya Hypnofivesic. Terapi ini merupakan kombinasi terapi hypnosis 5 jari dan music yang dikembangka oleh Prodi Keperawatan, Fakultas Kesehatan, Universitas Jenderal Achmad Yani. Terapi musik yang digunakan merupakan tipe Gregorian. Relaksasi hypnosis 5 jari dan terapi musik sudah banyak diteliti mampu menurunkan tingkat cemas dan stress [3]; [4].

\section{Metode}

Kegiatan pengabdian ini dilaksanakan di Posyandu Kunir V, Wirobrajan, Kota Yogyakarta. Pertama, Tim dari Universitas Jenderal Achmad Yani Yogyakarta berkoordinasi dengan kader. Hal ini perlu dilakukan mengingat situasi pandemic. Sehingga, protocol kesehatan perlu dilakukan. Maka, ibu yang menjadi peserta pengabdian masyarakat dikumpulkan diselasaran joglo dengan memperhatikan jarak dan penggunaan masker sepanjang acara.

Kemudian, tim memberikan video tentang terapi hypnofivesic. Terapi ini merupakan terapi kombinasi antara hypnosis 5 jari dan musik. Hypnofivesic merupakan terapi relaksasi yang dikembangkan dengan modifikasi musik. Terapi ini membutuhkan waktu 15 menit per sesi. Pengambilan data dilakukan sebelum terapi dan sesudah dilakukan terapi. Selanjutnya, peserta diminta untuk mengisi kuesioner Perceived Stress Scale (PSS), yaitu sebanyak 10 pernyataan. PSS membagi menjadi 3 kategori stress yaitu ringan $(0-13)$, sedang $(14-26)$, dan berat (>26). Kemudian hasil tersebut diuji menggunakan T-test, karena sebaran data normal Selain PSS, peserta juga diminta untuk mengisi data demografi yang terdiri dari usia ibu, usia anak, dan keluhan psikologis yang paling berat untuk saat ini. 


\section{Hasil dan Pembahasan}

\begin{tabular}{|c|c|c|c|}
\hline \multicolumn{4}{|c|}{ Tabel 1. Data Demografi } \\
\hline No & Kategori & $\begin{array}{l}\text { Mean } \\
\text { (SD) }\end{array}$ & $\%(N=14)$ \\
\hline \multirow{3}{*}{1} & Jenis Kelamin Anak & & \\
\hline & Laki-laki & & 42,9 \\
\hline & Perempuan & & 57,1 \\
\hline 2 & Usia Ibu & $\begin{array}{l}32,07 \\
(6,04)\end{array}$ & \\
\hline \multirow{4}{*}{3} & Ketakutan Ibu & & \\
\hline & $\begin{array}{l}\text { a. Tumbuh kembang } \\
\text { anak terganggu }\end{array}$ & & 21,43 \\
\hline & b. Makan anak & & 14,29 \\
\hline & c. Tertular Covid-19 & & 64,29 \\
\hline
\end{tabular}

Berdasarkan tabel didapatkan bahwa sebagian besar ibu memiliki anak perempuan yaitu $57,1 \%$ dengan rata-rata usia ibu yaitu 32 tahun. Pada masa ini termasuk dalam dewasa awal. Santrok menjelaskan bahwa dewasa awal berusia 21 - 39 tahun. Pada masa ini diharapkan mereka memiliki kontrol emosi yang matang dan memahami diri dengan baik[5]. Kematangan emosi merupakan keseimbangan antara emosi dengan otak yang menjembatani dunia dalam dan dunia luar dari individu tersebut[6]. Kematangan ini terbentuk dari pengalaman yang melibatkan pembelajaran emosional. Pengalaman tersebut dapat tersebut dapat berupa peristiwa buruk maupun menyenangkan yang dialami individu di masa perkembangan[7]. Hal ini sesuai dengan pengalaman ibu di Posyandu Kunir V di amsa pandemic. Saat ini, pandemi Covid 19 telah berlangsung selama satu tahun. Pembelajaran dari rumah untuk anak sekolah juga telah berlangsung lama. Hal ini menambah beban psikologis ibu selama pandemi Covid 19 berlangsung. Hal ini sejalan dengan penelitian Kusumastuti bahwa ibu memiliki selama masa pandemi, ibu mengalami peran ganda. Hal ini disebabkan karena ibu memiliki tekanan dalam peran sebagai ibu rumah tangga dan pekerjaannya[8]. Hal ini menimbukan stres bagi ibu. Selain itu, pada table juga terlihat bahwa ibu merasa bahwa takut anaknya akan tertular Covid-19, yaitu 64,29\%. Hal ini wajar dirasakan ibu, karena berdasarkan data dari UNICEF terdapat 930 kematian anak akibat Covid-19. Jumlah tersebut hanya $2 \%$ yang dilaporkan oleh seluruh provinsi yang ada di Indonesia[9].

Tabel 2. Uji T-Test

\begin{tabular}{clccc}
\hline Perlakuan & $\begin{array}{c}\text { Mean } \\
(\text { SD })\end{array}$ & t & df & $\begin{array}{c}\text { P } \\
\text { value }\end{array}$ \\
\hline Pre & $\begin{array}{l}20,93 \\
(5,4)\end{array}$ & & & \\
& $\begin{array}{l}20,29 \\
(5,99)\end{array}$ & 0,26 & 13 & 0,802 \\
\hline Post & & & & \\
\hline
\end{tabular}

Selain itu, data didapatkan bahwa p value yaitu $0,802(\mathrm{p}>0,05)$. Hal ini berarti bahwa terapi hypnosis lima jari dan musik (hypnofivesic) tidak memberikan dampak yang signifikan untuk penurunan stres. Hal ini bisa diakibatkan karena pertama suasana saat melakukan terapi dimana terlalu ribut. Pada saat dilakukan terapi banyak anak-anak berlalu lalang bahkan teriak-teriak. Hal ini sesuai dengan 
Nawawinetu \& Adriyani bahwa suara bising dapat mengakibatkan stres. Peningkatan stres ini akan mengurangi keefektifan terapi relaksasi yang dilakukan. Faktor kedua yang dapat mempengaruhi adalah fokus ibu terhadap anak[10]. Hal ini sesuai dengan kondisi di lapangan bahwa anak berlari-larian. Selain itu, tempat untuk posyandu berada di tepi jalan besar. Sehingga hal ini menambah ketakutan dan kecemasan ibu. Hal ini berdampak pada penurunan fokus ibu terhadap kegiatan yang sedang berlangsung. Selain itu, gambaran stres yang dialami ibu baik sebelum maupun sesudah latihan relaksasi berada pada rentang stres sedang. Hal ini mengindikasikan bahwa ibu memiliki banyak stressor ketika berada di rumah. Hal ini sesuai dengan yang diungkapkan ibu bahwa selama pandemic banyak kekhawatiran yang dipikirkan termasuk ekonomi keluarga, perkembangan anak, hingga tertularnya anak pada Covid-19. Hal ini sesuai dengan penelitian yang dilakukan Muslim bahwa pandemic Covid 19 berdampak pada stres keluarga, terutama ibu. Hal ini dikarena ibu harus mengurus pekerjaan rumah tangga, mendidik anak akibat sekolah dari rumah, dan bekerja untuk meningkatkan ekonomi keluarga[11]. Pendapat yang serupa juga diungkapkan Brown et al menungkapkan bahwa stressor selama pandemi bisa terjadi karena mood ibu yang kurang baik, dan kurang tidur. Hal-hal tersebut dapat diakibatkan karena double burden yang dialami ibu[12]. Oleh karena itu, untuk intervensi lebih lanjut, sebaiknya terapis memilih tempat yang kondusif agar hasil maksimal. Hal ini sesuai dengan yang dinyatakan Sari dan Subandi bahwa tempat yang kondusif dapat mempengaruhi hasil terapi relaksasi. Tempat tersebut memiliki pencahayaan yang tidak terlalu terang atau gelap serta audio visual juga baik [13]. Hal lain yang dapat mempengaruhi yaitu posisi nyaman. Saat terapi, ibu tidak duduk bersandar sehingga beberapa terlihat tidak nyaman. Hal ini ditunjukkan dengan sering bergeser. Penelitian lain juga mengatakan bahwa pasien yang akan melakukan tehnik relaksasi dianjurkan untuk duduk dengan nyaman [14][15].

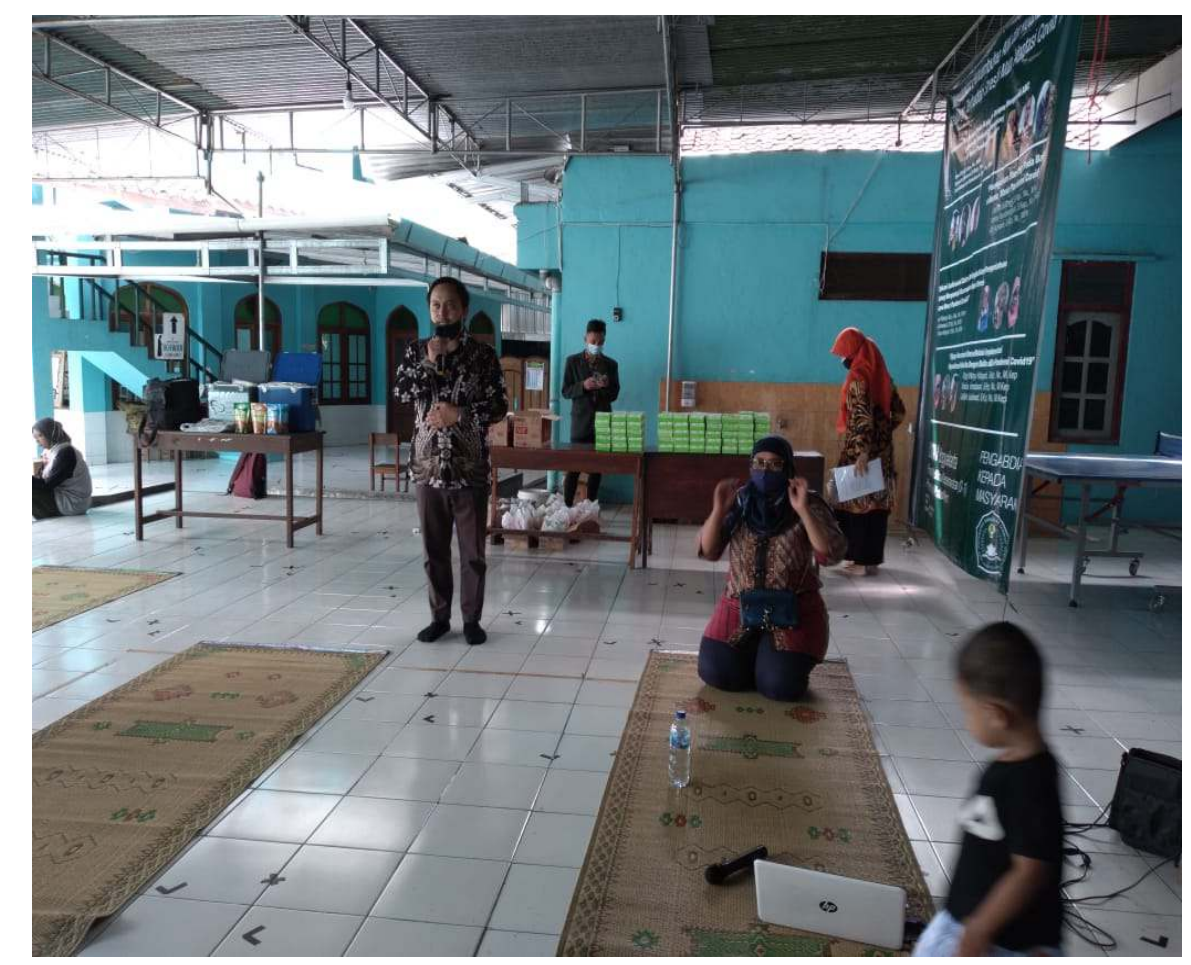

Gambar 3A. Penjelasan video Hypnotizes 


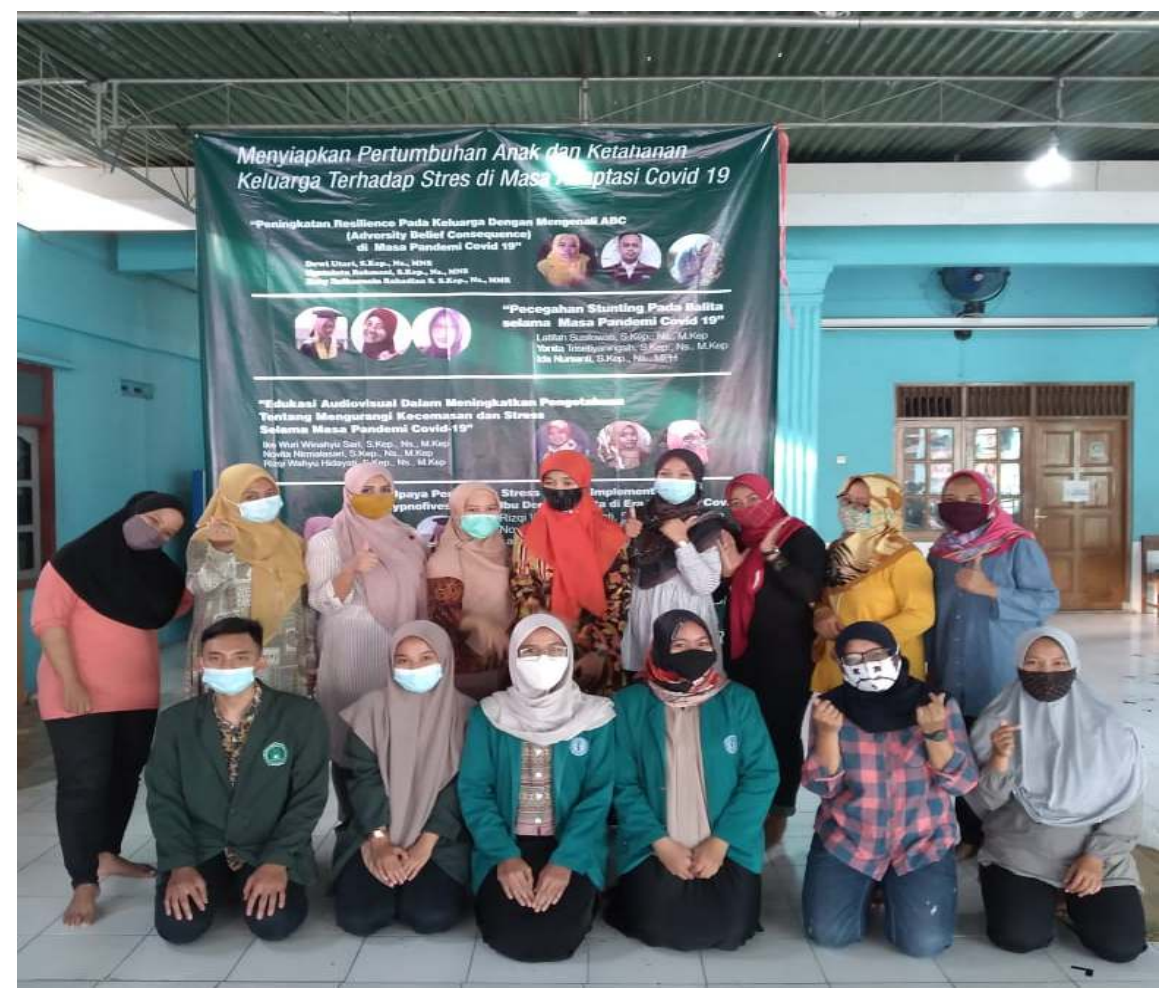

Gambar 3B. Dokumentasi bersama kader

\section{Kesimpulan}

Berdasarkan pencapaian yang ada saat kegiatan, maka perlu adanya kegiatan lanjutan antara lain: Pada tahap selanjutnya, kegiatan yang dapat direncanakan untuk keberlanjutan pengabdian masyarakat ini adalah: Memberikan pendidikan kesehatan tentang tehnik mengurangi stress dengan tempat yang kondusif (tidak dibarengkan dengan posyandu). Hal ini diharapkan mampu meningkatkan konsentrasi ibu dan memberikan pelatihan yang efektif untuk ibu.

\section{Ucapan terima kasih}

Kami mengucapkan terima kasih kepada kader Posyandu Kunir V yang telah membantu pelaksanaan pengabdian. Selain itu, kami juga mengucapkan terima kasih kepada Fakultas Kesehatan Universitas Jenderal Achmad Yani Yogyakarta yang telah memberikan bantuan dana untuk pelaksaan pengabdian tersebut.

\section{Daftar Pustaka}

[1] WHO, "Mental Health During Covid-19 Pandemic," 2019.

[2] CDC, "Covid-19 dan Anak-anak di Indonesia," 2020. .

[3] I. Nuvi et al., "KECAMATAN GUNUNG PATI KODYA SEMARANG," 2007.

[4] Aizid R., Sehat Dan Cerdas Dengan Terapi Musik. Laksana, 2011.

[5] D. R. Adila and A. Kurniawan, "Proses Kematangan Emosi Pada Individu Dewasa Awal yang Dibesarkan dengan Pola Asuh Orang Tua Permisif," Insa. J. Psikol. dan Kesehat. Ment., vol. 5, no. 1, p. 21, 2020, doi: 10.20473/jpkm.v5i12020.21-34.

[6] Landau, "The Self - The Global Factor of Emotional Maturity," Roeper Rev., vol. 20, no. 3, pp. 174-178, 1998.

[7] Nelson and Jarcho, "Growing Pains And Pleasures: How Emotional Learning Guides Development," Trends Cogn. Sci., vol. 18, no. 2, pp. 99 108, 2014. 
[8] A. N. Kusumastuti, "Dampak konflik peran ganda di masa pandemi covid19 pada ibu yang bekerja," no. 100, 2020.

[9] UNICEF, "COVID-19 dan Anak-Anak di Indonesia Agenda Tindakan untuk Mengatasi Tantangan Sosial Ekonomi," J. Educ. pshycology Couns., vol. 2, no. April, pp. 1-12, 2020.

[10] E. D. Nawawinetu and R. Adriyani, "Stress Akibat Kerja pada Tenaga Kerja yang Terpapar Bising," pp. 59-63, 2007.

[11] M. Moh, "Moh . Muslim : Manajemen Stress pada Masa Pandemi Covid-19 " 193," J. Manaj. Bisnis, vol. 23, no. 2, pp. 192-201, 2020.

[12] S. M. Brown, J. R. Doom, S. Lechuga-Peña, S. E. Watamura, and T. Koppels, "Stress and parenting during the global COVID-19 pandemic," Child Abus. Negl., vol. 110, no. June, 2020, doi: 10.1016/j.chiabu.2020.104699.

[13] A. D. K. Sari and Subandi, "Pelatihan teknik relaksasi untuk menurunkan kecemasan pada primary caregiver penderita kanker payudara," Gadjah Mada J. Prof. Psychol., vol. 1, no. 3, pp. 173-192, 2015.

[14] I. Z. Ekawaldi, Efektifitas Teknik Relaksasi Pernafasan untuk Mengurangi Kecemasan Atlet Futsal yang Hendak Bertanding, vol. 6, no. 1. 2017.

[15] Rahmawati, "Penerapan Teknik Relaksasi Nafas Dalam Pada Pasien Post Operasi Apendiktomi Dengan Gangguan Pemenuhan Kebutuhan Rasa Aman Nyaman Di Rsud Sleman.," 2018. [Online]. Available: http://eprints.poltekkesjogja.ac.id/1983/9/Kti Lutfiana.pdf. 